\title{
Transformation of the model of estimation of balance reliability UPS of the Russia in the account of correlation of the consumption regime
}

\author{
Yuri Chukreyev ${ }^{1, *}$ \\ ${ }^{1}$ Komi Scientific Center of the Ural Branch of the Russian Academy of Sciences, ISE and EPN, 167000, Russia
}

\begin{abstract}
The characteristics of the electric power consumption regime are used when determining the indicators of adequacy in the management of the development of the UPS of Russia. The influence of the changed conditions of their representation on the probabilistic indicators of the balance reliability of system-forming links between the territorial zones (UPS) of the computational model of the UPS of Russia is shown. On this basis, we proposed the transformation of the model of estimating the balance reliability indicators, which allows to increase the computational efficiency.
\end{abstract}

\section{Introduction}

When planning the development of the industry, the socalled balance of power for the UPS of the country as a whole and its unified EES (UPS) [1,2] was developed earlier, is being developed today and will be developed in the future. Its form includes two positions (Figure 1): the expenditure part "demand" (maximum load, export and standard power reserve); the incoming "cover" (installed power, unused power for the period of passage of the maximum, power inputs after passing the maximum, underutilization of power).

The issue that concerns both consumers and suppliers of electrical energy is to justify the regulatory power reserve, which is one of the components of the expenditure part of the balance sheet. In the tasks of long-term planning of EES it is called the full (normative) reserve, and conditionally divided into three components: repair, strategic and operational, intended to compensate for unscheduled (emergency) conclusions of the main generating and network equipment for repair. Therefore, in order not to confuse the concept of operational reserve in the current planning and shortterm (long-term), this component of the full reserve has recently been called the compensation reserve.

Market relations in the electric power industry exacerbate the issues of justifying the power reserve. With short-term planning (from 3 year to 4 years), the price for capacity during long-term (competitive) power take-off depends on the requirements for a full (normative) reserve in the conditions of market relations.

The difficulty in determining the total capacity reserve is mainly related to finding one of its three components - the operational (compensation) power reserve, which depends on a variety of factors and events, including those randomly determined [3 - 6, etc.]. These include:
- model of the calculation scheme of the UPS;

- disposable capacity structure of generating capacities;

- scheduled repairs of equipment;

- reduction of generating capacity of territorial zones due to emergency damage to power plant units;

- regular and irregular maximum loads of territorial zones and graphs of their changes in the context of the year and day;

- random deviations and irregular load fluctuations;

- reserves of communication capacity in normal and emergency modes between territorial zones.

The article considers the influence of modern possibilities of receiving and processing of probabilistically determined information on power consumption modes and the models of the UPS of Russia calculation schemes used to transform the methodology for estimating indicators adequacy (IA) and its means of support.

\section{Representation of a mode of power consumption}

Important, having a significant impact on IA and means of their provision in planning the development of EES is the question of presenting the power consumption regime during the settlement period, which usually is a year. The receipt of an hourly perspective schedule of power consumption of the territorial zones of EES for the settlement year at all times caused considerable difficulties.

Studies of balance reliability in our country began at the turn of the 60s of the last century. A generalization of these studies to the concentrated EES is given in [7]. As a yearly load graph, a load schedule was used for the duration in the hour section (8760 hours). As a criterion for making a decision to justify the reserve of power, the 
indicator of the integral probability of no-deficit work $\rho=1-J_{\text {д }}^{\text {опт. }}=0,999$. The index of the integral probability of occurrence of a power shortage $J_{\text {д }}^{\text {оाт. }}=0,001$ had its feasibility study and was determined by the expression $J_{\text {д }}^{\text {опт. }}=3_{R}^{\text {уд. } /\left(y_{0} \cdot 8760\right)[7] . ~ I n ~ t h i s ~ e x p r e s s i o n, ~ t h e ~ s p e c i f i c ~}$ reduced costs for reserve capacity ( 3 уд. $)$ were taken equal to 5 rub. / $\mathrm{kW}$, specific losses from non-supply of electricity to consumers $y_{0}=0.6 \mathrm{rub} . / \mathrm{kW} \cdot \mathrm{h}$.

In the same work, for the first time in the country, taking into account foreign experience, the concepts of the regular maximum of the load and its random deviations due to irregular oscillations and prediction errors were introduced. These concepts are included in almost all approved normative technical documents (NTD) - methodological instructive for the design of the development of power systems (hereinafter MI), used in our country and now. It should be noted that in these NTD introduced the concept of the average daily load schedule of the maximum power consumption of the days of December [2]. The distribution of this schedule is proposed for all 250 working days of the year (Figure 1). In those days, the reasons for justifying such an approach were understandable and understandable to the designers and the scientific community. In what it manifested itself.

In the methodical plan there was a transition from the certain seasonal interval of its decline) to the December maximum and the annual schedule of seasonal load decreases equalized. This was the main reason for the spread of the December average daily load schedule for all working days of the year. It should be noted that the same happened abroad, for example, in the power systems of North America, the balance sheet reliability standard is still applied in the form of $L O L E=0.1$ days / year, obtained on the basis of analysis of not 8760 hour changes in the load, but only it maximum values for each of 365 days of the year.

At present, the processes of obtaining the initial information on the levels of power consumption and the schedules for their change are significantly different from those that took place in the development of guidelines and MI. Today, it is possible to obtain realtime schedules of load changes in the power systems of the UPS of Russia in any time interval due to information:

- within the retrospective period about the actual capacity at the end of the hour ${ }^{1}$; actual daily average and average monthly temperatures; actual annual consumption of electrical energy;

- within the forecast period about the annual power consumption, set in the annual work of the schemes and programs of long-term development UPS Russia ${ }^{2}$.

The presence of such information allows to form the necessary data packet. It includes:

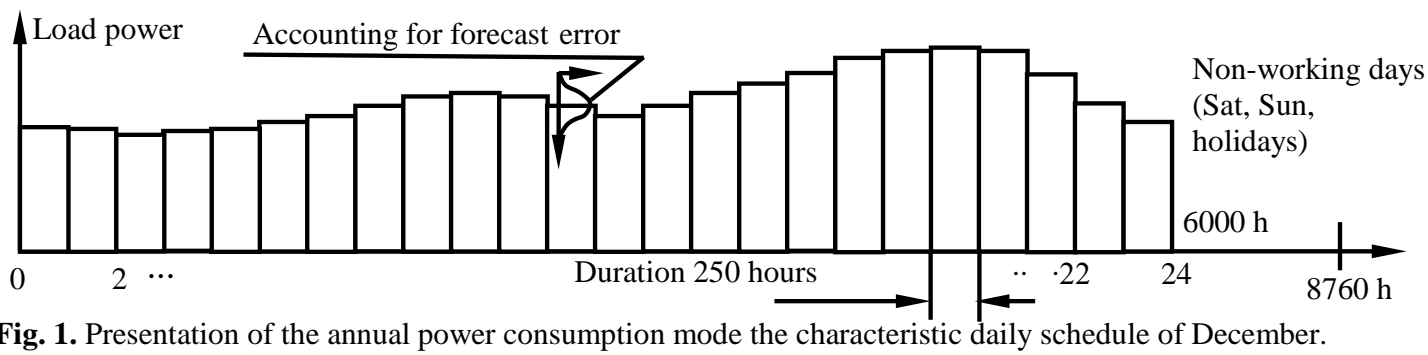

consideration of the UPS of the country not by a concentrated association, but by a multi-zone one with the separation as zones of joint EES. This required the development of a new approach to modeling the random states of generating capacity and the load in them with subsequent evaluation for satisfaction of all consumers. Considering 8760 hourly load changes has become, beyond time, an impossible task. The size of the decision criterion for justifying the capacity reserve also changed $\rho=1-J_{\text {д }}^{\text {Oाr. }}=0,999$. The indicator of the integral probability of the appearance of a power shortage, by virtue of a change in the principles of determining unit costs for standby capacity (the operating costs began to be taken into account) was adopted by the value $J_{\text {д }}^{\text {опा. }}=0,004$ [2].

The deficit of generating capacity in the country's UPS that was observed at that time did not allow for capital repairs during peak hours, which, unfortunately, is not observed today. They always fit into seasonal power failures. Thus, the load in them increased (assuming that repairs - this is an addition to the load in a
- the form of forecast daily average load charts;

- random deviations of the load from the mean values;

- the magnitude of the forecasted regular load maxima.

A description of the procedure for obtaining the above information is given in detail in [8]. A few words about the random component of load deviations from mean values. Her, with respect to the problem of balance reliability, at all times associated mainly with fairly wellestablished probabilistically determined events, caused by two reasons. The first one is caused by the appearance of deviations from the mean values of the daily schedule load (Figure 1), obtained as a result of processing a huge set of information on power consumption modes for a number of working days of the December month of the retrospective period. The second most significant reason is connected with taking into account the influence of the temperature factor on the

\footnotetext{
${ }^{1)}$ Daily dispatching lists of the operational information complex (OIC) of the main dispatch center (MDC) of SO UES JSC.

${ }^{2)}$ Scheme and program for the development of the UPS of Russia for 2016-2022.
} 
power consumption mode. It is no accident that in the unapproved Ministry of Energy of Russia in guidelines 2011 and in the Order of the Ministry of Energy of Russia $^{3}$, the prospective values of the maximum loads are given to the average annual temperatures of the outside air of the territory under consideration.

Statistical processing of power consumption modes for the 6-year period from 2010 to 2015 , carried out by the specialists of JSC "SO UPS" [8], allowed, according to the specified in the - within the forecast period about the annual power consumption, set in the annual work of the schemes and programs of long-term development UPS Russia for 2016-2022 annual electricity processing retrospective information, are almost $40 \%$ higher, given in the 2003 and $2011 \mathrm{MR}$. The same trend is observed for individual UPS, except for the Middle Volga UPS.

Coefficients of consumption covariance between the territorial zones identified in the form of UPS as a result of the processing of the retrospective information (the last of the items listed above) fluctuate within fairly wide limits. Of the 15 possible coefficients (6 UPS without the UPS of the Far East), more than 10 exceed the threshold of 0.5 . This indicates a strong dependence of random deviations in the load at once in several UPS, which largely affects IA and the means of their provision [8].

Table 1. Some load characteristics for the 2022 forecast year

\begin{tabular}{|c|c|c|c|c|c|c|c|}
\hline \multirow[b]{2}{*}{ Options } & \multirow{2}{*}{$\begin{array}{c}\text { UPS of Russia } \\
\text { without UPS of } \\
\text { the East }\end{array}$} & \multicolumn{6}{|c|}{ Name of UPS } \\
\hline & & Ural & Middle Volga & South & Nortwest & Centre & Siberia \\
\hline \multicolumn{8}{|c|}{ Load of territorial zones of the forecasted year, MW } \\
\hline irregular maximum ( $\left.P_{\text {нерег }}\right)$ & 155860 & 37390 & 17096 & 16831 & 15151 & 39266 & 30126 \\
\hline regular maximum $\left(P_{\max }\right)$ & 148592 & 36444 & 15949 & 16091 & 13789 & 36404 & 29915 \\
\hline \multicolumn{8}{|c|}{ Differences between irregular and regular highs (pu) } \\
\hline by the method of definition $P_{\max }[8]$ & 0,0466 & 0,0253 & 0,0671 & 0,0439 & 0,0900 & 0,0729 & 0,0070 \\
\hline in accordance with MU $1981 *$ & 0,0126 & 0,0161 & 0,0185 & 0,0189 & 0,0187 & 0,0153 & 0,0170 \\
\hline \multicolumn{8}{|c|}{ Random deviations of the load $\left(\sigma_{\Pi}\right)$ from the irregular maximum in pu } \\
\hline according to the above procedure & 0,0177 & 0,0409 & 0,0327 & 0,0468 & 0,0482 & 0,0389 & 0,0407 \\
\hline as in the MR-2003 and 2012 & 0,0127 & 0,0259 & 0,0382 & 0,0385 & 0,0406 & 0,0252 & 0,0288 \\
\hline
\end{tabular}

* the difference between irregular and regular highs $\Delta P_{\text {нерег }}=0,01 \cdot P_{\max }+1,24 \cdot \sqrt{P_{\max }}$

consumption volumes for the considered territorial zones

(UPS):

- regular load maxima;

- random deviations of the load from the mean values;

- average graphs of changes in daily loads;

- correlation dependencies of random load deviations.

The received information on the first two items for 2022 is given in Table 1. In the same table, the differences between regular and irregular load maxima are shown using different techniques. It can be seen that these differences are quite significant.

It should be understood that the methodology for obtaining a regular maximum based on the analysis of retrospective information is not entirely perfect in terms of using retrospective information on power consumption not listed in the middle temperature standards. Studies show that to describe the power consumption mode, you can use the shape of the load curve when using an irregular maximum as a maximum. The last two lines of the table show the values of the random deviations of the load $\left(\sigma_{n}\right)$, obtained by using different methods. It can be seen that they, obtained by

\footnotetext{
${ }^{3)}$ Order of the Ministry of Energy of Russia of 07.09.2010, No. 431 (Edited on August 17, 2017) "On approving the Regulations on the procedure for determining the amount of demand for capacity for conducting long-term power take-off ..." (Registered in the Ministry of Justice of Russia on 29.09.2010, No. 18578).
}

\section{Peculiarities of forming the model of the settlement scheme of the UPS of Russia for the tasks of adequacy.}

Under the zones of the same reliability (hereinafter the territorial zone is a concentrated system ${ }^{4}$ ) controlled in the analysis of balance reliability both under the conditions of a vertically integrated system and under the market management principle, a set of sets of territorial zones of EES for which network restrictions do not affect IA should be understood. In the future, this term will also be characterized by the phrase territorial area, i.e. the territory in which network restrictions do not affect the restriction of consumers in power and electricity.

With the long-term planning of the development of the UPS of Russia at all times, a number of various assumptions were adopted that made it possible to simplify the solution of the problem. This applies to the representation of the electricity consumption regime (only in December), the accounting for scheduled repairs and the composition and limitations of generating

\footnotetext{
4) A concentrated system is called a power system, within which there are no restrictions on power transmission in any possible emergency situations caused by unreliability of the generating and network equipment.
} 
equipment, and many other issues. The simplifications introduced during the long-term planning naturally concern also the issues of aggregating the scheme of electrical connections of the main generating and network objects.

It is clear that the introduced simplifications that have a certain influence on the decisions taken to manage the development of EES should have a certain justification. In any case, the model of the settlement scheme of the UPS of Russia for determining IA in order to justify the reserve capacity values should be represented by a graph containing links to nodes (territorial zones) of contiguity. The territorial zone is a kind of association in which network restrictions do not affect the power distribution. Linkages are understood as a set of power transmission lines between territorial zones. The communications of the calculated graph should contain information on maximum permissible overflows (MPO) of capacity (connectivity capacity) in the forward and reverse directions for normal and emergency operation.

In recent years (2010-2015) in the circles of reservation researchers there have been judgments that in the calculations aimed at determining the requirements for the levels of the operational reserve capacity for the short-term period (from 1 to 7 years), the UPS scheme of Russia should be more detailed with the inclusion of up to 100 or more territorial zones. When developing power and power balances for a more distant future, there were no doubts that territorial zones could be represented in a more aggregated form, for example, in the form of united power system (UPS) or free power transfer zones (FPTZ) [6], with possible breakdown of them on sections that limit emergency mutual assistance within them. In any case, the number of territorial zones did not exceed 20.

It is clear that the correct solution of these issues requires the conduct of relevant studies. In the period 2012-2016 such studies in solving a set of issues related to the development of the UPS of Russia were carried out at Joint Stock Company «Scientific and Technical Center of Unified Power System»., which is the basic scientific center of JSC «SO UPS» [9]. Unfortunately, at the present time, the information necessary for the scientific substantiation of these issues is practically closed to researchers dealing with issues of adequacy. In this article, the authors relied on information support received in the course of a number of works with JSC "SO UPS of Russia" in the period 2011-2016.

In 2011-2012. on the instructions of JSC «SO UES» JSC "STC UPS" performed work on the formation of the model of the settlement scheme of the UPS of Russia for solving the problems of ensuring their adequacy [9] It is quite obvious that in order to evaluate the IA of the actual composition of the generating equipment, their accidents, and the projected maximum loads, such schemes are of some interest from the perspective of obtaining IA in the territorial zones and identifying "weak" links in the system. At the same time, solving the task of justifying the means of ensuring adequacy operational (compensatory) capacity reserves for such schemes is, in our opinion, rather problematic.

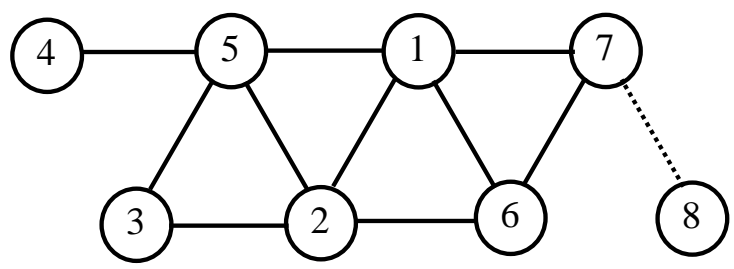

Fig. 2. Model of the settlement scheme of the UPS of Russia:

1 - UPS Urala; 2 - UPS of the Middle Volga;

3 - UPS of the South; 4 - UPS of the North-West;

5 - UPS of the Center; 6 - Kazakhstan; 7 - UPS of

Siberia; 8 - UPS East.

On the basis of the developed 56-node model of the design scheme of the UPS of Russia, with the participation of experts from the regimes service of JSC "SO UPS", a design scheme consisting only of UPS was developed (Figure. 2). Information filling on the territorial zones (the composition of the generating equipment, the rate of its failure rate, the form of the change in the daily load schedule, the forecast errors and their correlation dependencies), on the connections (throughput and accidents) was obtained partly work from the schemes and programs of long-term development Russian Unified Power System for 20162022, partly as a result of processing of retrospective information on the reporting parameters of the system operation for 2010-2016.

\section{Opportunities for transforming the model for justifying the operational reserve of capacity, in relation to the current conditions for the development of the UPS of Russia}

Analysis of the results of determining the operational (compensation) capacity reserve, presented in Table 2 and 3 for 2022 (the schemes and programs of long-term development Russian Unified Power System for 20162022) allows us to take a slightly different look at the formulation of the task of estimating IA in planning the development of the UPS of Russia in the current conditions for receiving and processing retrospective information on power consumption regimes. Specifically, this relates to the retrospective information revealed as a result of statistical processing, the dependence of the change in the power consumption mode due to random errors in forecasting the load between different territorial zones. The effect of this factor in Table 2 and 3 are termed with and without correlation.

Presented in Table 2 the results of the distribution of the operational capacity reserve for UPS of Russia are of a research nature. The reason is insufficiently worked out and practically not discussed at the conferences the questions on the formation of the initial information on the maximum permissible power flows in the models of the settlement scheme of the UPS of Russia presented by the JSC "SO UPS". 
Table 2 - Distribution of the operational (compensation) reserve for the ECO with different presentation of the model of the settlement scheme of the UES of Russia for 2022. (information from the work of CIPR UES of Russia for 2016-2022)

\begin{tabular}{|c|c|c|c|c|c|c|c|}
\hline \multirow[b]{2}{*}{ Options } & \multirow{2}{*}{$\begin{array}{l}\text { UPS of Russia } \\
\text { without UPS of } \\
\text { the East }\end{array}$} & \multicolumn{6}{|c|}{ Name of UPS } \\
\hline & & Ural & $\begin{array}{l}\text { Middle } \\
\text { Volga }\end{array}$ & South & Nortwest & Centre & Siberia \\
\hline Irregular maximum loads & 155860 & 37390 & 17096 & 16831 & 15151 & 39266 & 30126 \\
\hline \multicolumn{8}{|c|}{ Taking into account the correlation of the load } \\
\hline \multicolumn{8}{|c|}{56 territorial zones, the complete scheme of the UPS of Russia [9] } \\
\hline Operational reserve, & 15950 & 4914 & 1112 & 1682 & 1713 & 3393 & 3136 \\
\hline$\%$ & 10,23 & 13,14 & 6,50 & 9,99 & 11,30 & 8,64 & 10,41 \\
\hline \multicolumn{8}{|c|}{7 territorial zones (6 UPS of Russia + Kazakhstan, figure 2) } \\
\hline Operational reserve, & 15610 & 4894 & 1078 & 1619 & 1629 & 3365 & 3025 \\
\hline$\%$ & 10,02 & 13,09 & 6,31 & 9,62 & 10,75 & 8,57 & 10,04 \\
\hline \multicolumn{8}{|c|}{ without taking into account the bandwidth of communications (UPS of Russia as one node) } \\
\hline Operational reserve, & 14754 & & & & & & \\
\hline$\%$ & 9,47 & & & & & & \\
\hline Differences in \% to original & 5,48 & & & & & & \\
\hline \multicolumn{8}{|c|}{ Without taking into account load correlation } \\
\hline \multicolumn{8}{|c|}{56 territorial zones, the complete scheme of the UPS of Russia [9] } \\
\hline Operational reserve, & 12735 & 4075 & 125 & 1280 & 1700 & 2885 & 2670 \\
\hline$\%$ & 8,17 & 10,90 & 0,73 & 7,61 & 11,22 & 7,35 & 8,86 \\
\hline \multicolumn{8}{|c|}{7 territorial zones (6 UPS of Russia + Kazakhstan, figure 2} \\
\hline Operational reserve, & 11915 & 3894 & -25 & 1189 & 1609 & 2793 & 2455 \\
\hline$\%$ & 7,64 & 10,41 & $-0,16$ & 7,06 & 10,62 & 7,11 & 8,15 \\
\hline \multicolumn{8}{|c|}{ without taking into account the bandwidth of communications (UPS of Russia as one node) } \\
\hline Operational reserve, $\quad \mathrm{MW}$ & 10915 & & & & & & \\
\hline$\%$ & 7,00 & & & & & & \\
\hline Differences in $\%$ to original & 8,39 & & & & & & \\
\hline
\end{tabular}

Table 3. Bandwidth of communications (MW) and ratio multiplicity optimal integral probability of power shortage in the UPS (0.004) to the value of the integral probability of link overloading

\begin{tabular}{|c|c|c|c|c|c|c|c|c|c|c|c|}
\hline \multicolumn{2}{|c|}{} & \multicolumn{7}{|c|}{ The numbers of ties in the UPS of Russia in the form of UPS (Figure 2) } \\
\cline { 2 - 12 } & $1-2$ & $1-5$ & $1-6$ & $1-7$ & $2-3$ & $2-5$ & $3-5$ & $4-5$ & $6-7$ \\
\hline \multirow{2}{*}{$\begin{array}{c}\text { Throughput } \\
\text { Without taking into account the } \\
\text { correlation }\end{array}$} & 3175 & 687 & 3133 & 840 & 990 & 2185 & 1490 & 2400 & 3285 \\
\hline & 27 & 22 & 7,4 & 7,4 & 12 & 120 & 5,6 & 39 & 9999 \\
\hline \multicolumn{2}{|c|}{$\begin{array}{c}\text { in the opposite } \\
\text { Taking into account the correlation }\end{array}$} & 88 & 84 & 41 & 41 & 70 & 2700 & 73 & 103 & 9999 \\
\hline
\end{tabular}

The results given in Table 2 show that when the levels of the MPO of communications both inside the UPS (here not shown) and between them are received at JSC "SO UPS" (Table 3), the differences in the reservation levels of the territorial zones are extremely insignificant. The explanation for this is quite simple: in power system associations, the MPO (transfer capacity) of connections practically do not limit the transfer of power from one node to another. Moreover, attention is drawn to the fact that when the correlation dependencies between random load deviations in the territorial zones (UPS) are taken into account, the influence of the MPO of the bonds on the IA decreases drastically. In Table 3 shows such relationships, for example, if the integrated probability of a power shortage in the UPS is close to 0.004 for the optimal variant of the development of the UPS of Russia, then for the Ural-Center connection (1-5, in Figure 2) without taking into account the correlation, the probability of overloading its MPO is 0,000119 (multiplicity $0,004 / 0,00018=22$, in Table 3). Taking into account the correlation leads to a reduction of more than threefold the probabilities of MPO overloading. For the communication in question, it was 0.000048 .

All this leads to the possibility of considering the UPS of Russia in the form of a concentrated power system in which the simulation of random states of generation and especially the load is made at the level of territorial zones, taking into account the dependencies of their random deviations between themselves. The evaluation of the generated state for the purpose of providing the load is made by simply comparing the total for all territorial zones of the model of the calculation scheme of the UPS of Russia, the values of generation and load. 
Adopting such an approach dramatically reduces the time required to obtain a preliminary result. Cost reduction occurs due to the exclusion from the consideration in the IA estimation model of the most costly in the temporal aspect of the block of estimating the random state of the system $[5,6]$. Then this result can be corrected already taking into account the maximum allowed power flows. From Table 2 that the introduced simplifications in the variant taking into account the correlation lead to a decrease in the compensation power reserve by only $0.75 \%$ in relation to the irregular maximum of the load, and if to the reserve capacity, it is only $5.5 \%$.

\section{References}

1. Methodical recommendations on designing the development of power systems. (Approved by Order of the Ministry of Energy of Russia of June 30, 2003, No. 281). - M: Ministry of Energy of the Russian Federation, SO 153-34.20.118-2003.

2. I.M. Wolkenau, A.N. Zeyliger, L.D. Khabachev Economics of the formation of electric power systems. - Moscow: Energoatomizdat. (1981) - 320 p.

3. G.A. Volkov . Optimization of reliability of electric power systems. - Moscow: Nauka, (1986) - 117 p.

4. G.F. Kovalev, L.M. Lebedeva Reliability of power systems. - Novosibirsk: Science, (2015) - 224 p.

5. Yu.Ya. Chukreev. Models for ensuring the reliability of electric power systems. - Syktyvkar: Komi Scientific Center of the UrB RAS, (1995) -176 p.

6. Yu.Ya. Chukreev, M.Yu. Chukreev. Models for estimating the indicators of balance reliability in the management of the development of electric power systems. - Syktyvkar: Komi Scientific Center of the Ural Branch of the Russian Academy of Sciences, (2014) - 207 p.

7. I.M. Markovich. Modes of energy systems. Moscow: Energia, (1969) $351 \mathrm{p}$.

8. Yu.Ya. Chukreev, M.Yu. Chukreev, V.S. Chuprov Characteristics of the electric power consumption regime applied to the problems of balance reliability in the management of the development of electric power systems. Results / Methodological issues of reliability research of large energy systems. Issue. 68 . - Irkutsk: ISEM SB RAS, (2017) - P. 328-337.

9. Yu.Ya. Chukreev. Features of the evaluation of the balance-of-life indicators for the long-term development of the UPS of Russia / / Methodological issues of reliability research of large energy systems. Issue.65. - Irkutsk: Reliability of liberalized energy systems - ISEM SB RAS, (2015). - P. 213-222. 